\title{
Analisis Implementasi Kanvas Model Bisnis pada CV Cipta Karya
}

\author{
Mirrah Fitriana Maghfiroh \\ Program Pascasarjana Institut Seni Indonesia Yogyakarta, \\ Jalan Suryodiningratan No. 8, Yogyakarta-55143 \\ E-mail:mirrah.fitri13@gmail.com
}

\begin{abstract}
ABSTRAK
CV Cipta Karya merupakan perusahaan penyedia kebutuhan marching band yang terletak di Daerah Istimewa Yogyakarta. Setelah dua tahun berdiri secara resmi dan memiliki legalitas perusahaan ini belum merumuskan sebuah model bisnis dan melakukan evaluasi secara mendalam baik internal maupun eksternal sehingga disusun kanvas model bisnis yang terdiri dari sembilan blok yang saat ini sedang dijalankan. Terdiri dari segmentasi pelanggan, proposisi nilai, saluran, hubungan pelanggan, arus pendapatan, sumber daya utama, aktivitas utama, kemitraan utama, dan struktur biaya. Kemudian dilakukan evaluasi terhadap kanvas model bisnis tersebut. Penelitian ini menggunakan metode kualitatif deskriptif dengan melakukan pengumpulan data, menganalisis, dan menyimpulkan fakta-fakta yang diperoleh di lapangan. Data diperoleh dari wawancara dengan direktur, melakukan evaluasi internal terhadap kanvas model bisnis dengan para karyawan menggunakan analisis SWOT yang terdiri dari kekuatan, kelemahan, peluang, dan ancaman bagi perusahaan, serta dilakukan evaluasi eksternal dengan wawancara terhadap pelanggan yang pernah membeli dan menggunakan produk CV Cipta Karya berdasarkan analisis peta empati. Peta empati terdiri dari apa yang dilihat, dipikirkan dan dirasakan, didengar, dikatakan dan dilakukan, dikorbankan, serta diperoleh pelanggan. Analisis SWOT bertujuan untuk mempermudah perusahaan dalam melakukan inovasi dan perbaikan karena dilakukan evaluasi secara mendalam dan terstruktur. Evaluasi dengan peta empati bertujuan untuk mengetahui pengalaman yang dialami oleh pelanggan selama menggunakan produk $\mathrm{CV}$ Cipta Karya sehingga inovasi yang dilakukan perusahaan sesuai dengan kebutuhan di lapangan. Berdasarkan hasil analisis lebih dalam terhadap data yang terkumpul maka, diperoleh lima poin tambahan perubahan dalam kanvas model bisnis yang terdapat pada blok kemitraan utama, proposisi nilai, hubungan pelanggan, dan saluran. Setelah ditemukan kanvas model bisnis yang baru diharapkan akan diimplementasikan oleh CV Cipta Karya dan menjadi acuan untuk evaluasi secara berkala.
\end{abstract}

Kata kunci: kanvas model bisnis, peta empati, analisis SWOT

\section{The Analysis of Implementation Business Model Canvas at the CV Cipta Karya ABSTRACT}

CV Cipta Karya is a company that provides marching band necessities is in the Special Region of Yogyakarta. After being officially established for two years and it has legality, the company does not do any internal or external evaluation and formulated its business model yet. Therefore, the business model canvass that consists of nine blocks has been arranged and it is being operated now. The business model canvass consists of customer segments, value proposition, channels, customer relationships, revenue streams, key resources, key activities, key partnerships, and cost structure. After that, the internal evaluation toward the business model canvass. This study used a descriptive qualitative method by collecting data, analysing, and concluding the facts obtained from observation. Data were obtained from interviews with directors, conducted an evaluation toward the canvass of model business was carried out by conducting a discussion with workers using SWOT consists of strengths, weaknesses, opportunities, 
and threats for the company. Besides, the external evaluation from the customer's view by interviewing who had purchased and used CV Cipta Karya products based the analysis of empathy map. Empathy map consists of what is seen, thought and felt, heard, said and done, sacrificed, and obtained by customers. SWOT analysis aims to make it easier for companies to innovate and improve because it is carried out with an in-depth and structured evaluation. Evaluation with empathy map aims to know what customers experienced while becoming the customer of CV Cipta Karya products so that the innovations made by the company are in accordance with the necessities in the market. Based on the deeper analysis, there are five additional points of changing in the canvass of the business model such as key partnership, value proposition, customer relationship, and channels. After finding the new business model canvas, it is hoped that CV Cipta Karya will implement it and become a reference for regular evaluation.

Keywords: business model canvas, empathy map, SWOT analysis

\section{PENDAHULUAN}

Berdasarkan pengamatan sejak 2017, unit-unit marching band di berbagai daerah di Indonesia semakin banyak bermunculan, dari tingkat Taman Kanakkanak (TK), Sekolah Dasar (SD), Sekolah Menengah Pertama (SMP) atau sederajat, Sekolah Menengah Atas (SMA) atau sederajat, universitas, hingga instansi pemerintah seperti Dinas Pendidikan, Dinas Pemuda dan Olah Raga, serta Dinas Pariwisata. Marching band tidak bisa dipisahkan dengan berbagai kebutuhan untuk latihan hingga tampil seperti tenaga pelatih, properti, kostum, dan alat musik. Oleh karena itu, dibutuhkan produsen atau distributor untuk memenuhi kebutuhan tersebut. Produsen atau distributor ini akan lebih dipercaya jika berbentuk sebuah perusahaan yang telah memiliki perizinan usaha secara legal. Perusahaan yang telah memiliki legalitas di Indonesia salah satunya adalah CV Cipta Karya.

CV Cipta Karya berdiri secara resmi pada tanggal 9 Januari 2019. Perusahaan ini bergerak di bidang kontraktor, produsen, serta distributor barang dan jasa. Penjualan barang berfokus pada alat musik, kostum, dan perlengkapan marching band. Penawaran jasa berfokus pada pelatih dan praktisi marching band. Selama dua tahun berdiri, CV Cipta Karya masih fokus pada target-target penjualan dan promosi agar merek tersebut semakin dikenal oleh berbagai unit marching band di seluruh Indonesia. CV Cipta Karya belum memiliki model bisnis yang memang dikonsep dengan cara tertulis sehingga belum pernah dilakukan evaluasi secara internal, yaitu dengan melakukan diskusi bersama karyawan maupun eksternal dengan cara meminta ulasan dari para konsumen secara rinci. Adanya evaluasi ini sangat penting bagi perkembangan dan kemajuan suatu perusahaan.

Model bisnis digunakan oleh perusahaan sebagai alat dalam perumusan strategi bisnisnya. Osterwalder dan Pigneur (2012) menyebutkan bahwa sebuah model bisnis menggambarkan dasar pemikiran tentang bagaimana organisasi menciptakan, memberikan, dan menangkap nilai. Model bisnis dijelaskan melalui sembilan blok bangunan dasar yang mencakup empat bidang utama dalam suatu 
bisnis, yaitu pelanggan, penawaran, infrastruktur, dan kelangsungan finansial (Osterwalder dan Pigneur; 2012). Sembilan blok tersebut adalah Segmentasi Pelanggan (Customer Segments), Proposisi Nilai (Value Proporsitions), Saluran (Channels), Hubungan Pelanggan (Customer Relationships), Arus Pendapatan (Revenue Streams), Sumber Daya Utama (Key resources), Aktivitas Utama (Key Activities), Kemitraan Utama (Key Partnerships), dan Struktur Biaya (Cost Structure). Kesembilan blok bangunan model bisnis ini akan menjadi alat bantu ringkas yang disebut dengan Business Model Canvas (Kanvas Model Bisnis). Business Model Canvas ini yang akan diimplementasikan pada CV Cipta Karya serta akan dianalisis secara internal menggunakan SWOT dan eksternal menggunakan peta empati pelanggan.

Menurut Rangkuti di dalam Analisis SWOT dengan Metode Kuesioner (Salim, Siswanto, 2019), kinerja pengembangan ataupun organisasi dapat ditentukan oleh kombinasi faktor internal dan eksternal. Kedua faktor tersebut harus dipertimbangkan dalam analisis SWOT. Menurut Salim dan Siswanto (2019) analisis SWOT adalah identifikasi berbagai faktor secara sistematis untuk merumuskan strategi. Analisis ini didasarkan pada hubungan atau interaksi antara unsur-unsur internal, yaitu kekuatan dan kelemahan terhadap unsur-unsur eksternal, yaitu peluang dan ancaman. Analisis SWOT ini yang digunakan untuk mengevaluasi kanvas model bisnis CV Cipta Karya secara internal, sedangkan dari eksternal akan dilakukan analisis berdasarkan wawasan pelanggan. Osterwalder dan Pigneur (2012) menyebutkan bahwa desain model bisnis yang baik, melihat model bisnis dari sisi pelanggan, sebuah pendekatan yang mengarah pada ditemukannya peluang yang benar-benar baru. Pemikiran pelanggan bukan satusatunya titik awal inisiatif untuk inovasi, tetapi kita harus melibatkan persektif pelanggan ketika mengevaluasi model bisnis. Pelanggan merupakan salah satu aset penting bagi perkembangan suatu perusahaan maka, CV Cipta karya harus bersedia mendengarkan pendapat para pelanggan tentang produknya. Selain itu, bisa menjadi acuan untuk membuat sebuah inovasi.

Dari latar belakang yang telah dijelaskan maka peneliti berasumsi akan lebih baik jika CV Cipta Karya memiliki sebuah strategi bisnis yang dirancang secara tertulis dengan menerapkan business model canvas yang telah dianalisis berdasarkan analisis SWOT dan peta empati pelanggan. Hal ini dimaksudkan untuk mempermudah CV Cipta Karya dalam melakukan evaluasi dan inovasi serta memahami lebih mendalam yang terjadi di lapangan.

\section{METODE PENELITIAN}


Metode yang digunakan dalam penelitian ini adalah kualitatif deskriptif dengan melakukan pengumpulan data, menganalisis secara kritis, dan menyimpulkan berdasarkan fakta-fakta yang diperoleh. Sumber data yang dikumpulkan berasal dari data primer dan data sekunder.

Data primer didapatkan melalui tiga sumber, yaitu wawancara dengan Dhiya'ul Fajri selaku pendiri sekaligus Direktur CV Cipta Karya, diskusi dengan karyawan kantor untuk melakukan analisis SWOT, dan wawancara terhadap pelanggan yang pernah membeli dan menggunakan alat dan/atau jasa dari CV Cipta Karya. Pelanggan yang menjadi narasumber dipilih secara acak tanpa mencantumkan identitas agar diperoleh jawaban sebenarnya berdasarkan pengalaman mereka. Data sekunder berdasarkan literasi dan dokumen-dokumen yang melengkapi data penelitian. Dokumen didapatkan melalui data kantor serta media sosial CV Cipta Karya. Literasi berasal dari buku dan jurnal untuk melengkapi data-data penulisan.

Teknik analisis data dalam penelitian ini adalah analisis deskriptif, yaitu dengan mendeskripsikan sembilan elemen bisnis model kanvas yang dinilai dan dievaluasi dengan analisis SWOT serta dilakukan analisis peta empati pelanggan sehingga tercipta bisnis model kanvas yang baru.

\section{HASIL DAN PEMBAHASAN}

\section{A. Gambaran Umum Perusahaan}

Perusahaan ini mulai dirintis sejak tahun 2016 oleh Dhiya'ul Fajri, S.Pd., M.Sn. Saat itu Fajri belum memiliki perusahaan sendiri. Memulai sebagai reseller alat sekaligus praktisi marching band, kemudian berinisiatif untuk mem-branding dirinya sebagai penjual alat marching band. Dia aktif mempromosikan dirinya kepada komunitas, pelatih-pelatih, serta unit-unit marching band di Indonesia. Pada tahun 2019, CV Cipta Karya resmi berdiri dengan memiliki legalitas. Saat ini lokasi kantor dan tempat produksi terletak di Jalan Semar No. 83, Sidorejo RT 008, Ngestiharjo, Kasihan, Bantul, DIY-55182.

CV Cipta Karya menjadi produsen alat perkusi dengan merek Maxpro. Merek ini merupakan produk milik CV Cipta Karya. Selain itu juga sebagai produsen alat-alat colorguard, yaitu bendera, rifle, sabre, airblade, dan propertinya serta kostum unit untuk pemain musik, colourguard, dan mayoret. Perusahaan ini juga berperan sebagai distributor resmi alat tiup brass dan alat-alat yang dibutuhkan dalam marching band yang belum bisa diproduksi sendiri. Selain barang, CV Cipta Karya juga menyediakan jasa praktisi marching band, seperti pelatih lapangan, arranger musik, dan pembuat display.

Setelah dua tahun berdiri, CV Cipta Karya telah memiliki 15 karyawan yang terdiri dari direktur, divisi produksi, divisi pemasaran, divisi administrasi dan 
keuangan, divisi kontraktor, dan karyawan perajin. Memiliki 15 reseller yang disebut dengan sales executive yang tersebar di beberapa daerah. Omset yang dihasilkan per bulan, rata-rata dua ratus juta rupiah. Apabila pesanan sedang ramai dan memperoleh proyek besar, maka omsetnya bisa mencapai satu setengah miliar rupiah. Data ini berdasarkan laporan keuangan perusahaan yang ditunjukkan oleh Fajri.

\section{B. Kanvas Model Bisnis CV Cipta Karya}

Kanvas model bisnis CV Cipta karya yang dirumuskan berdasarkan data yang diperoleh melalui wawancara dengan Dhiya'ul Fajri adalah sebagai berikut:

\section{i. Segmentasi Pelanggan (Customer Segmentation)}

Pelanggan merupakan unsur penting agar sebuah perusahaan dapat bertahan. Saat ini pelanggan utama CV Cipta Karya adalah unit marching band yang melakukan pengadaan alat, mulai dari marching band sekolah, marching band pemerintah, hingga marching band perusahaan yang membutuhkan alat dengan kualitas baik dengan harga yang kompetitif.

\section{ii. Proposisi Nilai (Value Proposition)}

Proposisi nilai merupakan alasan pelanggan untuk bersedia beralih dari perusahaan satu ke perusahaan yang lain karena mereka merasa perusahaan tersebut memiliki inovasi baru yang lebih menarik dan efisien. CV Cipta Karya menawarkan desain produk alat musik yang futuristis terutama pada alat perkusi Maxpro. Kualitas suara mampu bersaing dengan merek yang harganya lebih mahal dibanding produk CV Cipta Karya. Ditawarkan garansi selama satu tahun untuk semua alat musik. Pelayanan konsumen yang profesional juga menjadi salah satu keunggulan yang dimiliki.

\section{iii. Saluran (Channels)}

Saluran menggambarkan cara sebuah perusahaan berkomunikasi dengan segmen pelanggan dan menjangkau mereka untuk memberikan proporsi nilai. Ada beberapa cara yang dilakukan oleh CV Cipta Karya untuk menyalurkan dan mempromosikan produk perusahaan kepada unit marching band sebagai berikut:

1) Pelatih

Untuk menjangkau unit-unit marching band dengan cara melalui para pelatih. Sebab para pelatih merupakan orang yang memiliki peranan penting dan berpengaruh dalam sebuah unit.

2) Media sosial 
Media sosial merupakan sarana media yang efektif untuk mempromosikan suatu produk. CV Cipta Karya memanfaatkan peluang ini dengan baik. Perusahaan ini melengkapi berbagai akses media sosial dengan memiliki akun di berbagai aplikasi, yaitu WhatsApp, Instagram, Facebook, Shopee, Siplah, dan memiliki website.

\section{3) Booth event}

Event merupakan kesempatan untuk memperkenalkan produk kepada para konsumen secara langsung. Pada tahun 2019 CV Cipta Karya membuka lapak di acara kompetisi nasional, yaitu Hamengku Buwono Cup 2019 di Yogyakarta dan Grand Prix Marching Band 2019 di Jakarta. Hal ini bertujuan agar para calon pelanggan bisa melihat dan menggunakan secara langsung produk-produk CV Cipta Karya.

4) Sales executive

Pada tahun 2021, sales executive berjumlah 15 orang yang berada di beberapa daerah yaitu, Yogyakarta, Semarang, Medan, Aceh, Kutai, Banjarmasin, Pontianak, Bengkulu, dan Lampung.

5) Membuat event

Event yang sudah diselenggarakan adalah Maxpro Drum Battle di Medan. Event tersebut khusus untuk pertandingan antarpemain perkusi. Sasarannya memang untuk mempromosikan produk merek Maxpro.

\section{iv. Hubungan Pelanggan (Customer Relationship)}

Untuk berkomunikasi dan menjaga hubungan dengan pelanggan, CV Cipta Karya memiliki cara yang berbeda-beda tergantung dari status pelanggan tersebut. Untuk menjalin hubungan dengan para pelatih dan unit marching band itu sendiri maka, dilakukan pendekatan secara personal oleh direktur. Fajri mengenalkan serta menjelaskan secara detail produk dan sistem CV Cipta Karya dalam menangani pembelian. Jika pelatih-pelatih menjadi pelanggan CV Cipta Karya akan ada komisi sesuai kesepakatan.

\section{v. Arus Pendapatan (Revenue Streams)}

Arus pendapatan menggambarkan uang tunai yang dihasilkan perusahaan dari segmen pelanggan. Pendapatan utama CV Cipta Karya diperoleh melalui penjualan alat-alat marching band. Pendapatan lain berasal dari penawaran jasa kepelatihan, arranger musik, dan pembuat display. Ada juga pendapatan dari penjualan alat musik tidak untuk marching band.

\section{vi. Sumber Daya Utama (Key Resources)}


Sumber daya utama menggambarkan aset-aset terpenting yang diperlukan agar sebuah model bisnis dapat berfungsi. Sumber daya ini memungkinkan perusahaan menciptakan dan menawarkan proporsi nilai, menjangkau pasar, mempertahankan hubungan dengan segmen pelanggan, dan memperoleh pendapatan. Sumber daya utama CV Cipta Karya adalah kantor, tempat produksi, kendaraan perusahaan, karyawan kantor, karyawan perajin, dan legalitas.

\section{vii. Aktivitas Utama (Key Activities)}

Aktivitas utama, yaitu tindakan-tindakan terpenting yang harus diambil perusahaan agar dapat beroperasi dengan sukses. Aktivitas utama CV Cipta karya saat ini adalah memproduksi alat perkusi Maxpro, alat colourguard, dan kostum, menjadi distributor resmi alat-alat marching band, serta sebagai kontraktor.

\section{viii. Kemitraan Utama (Key Partnership)}

Perusahaan menciptakan aliansi untuk mengoptimalkan model bisnis, mengurangi risiko, atau memperoleh sumber daya mereka. Kemitraan CV Cipta Karya saat ini adalah orang yang berperan sebagai pemegang merek produk alat marching band agar bisa menjadi distributor resmi sehingga harga yang ditawarkan di pasaran tetap sama. Kemudian, bermitra pula dengan ekspedisi untuk mengirimkan barang agar memperoleh harga khusus. Selain itu, juga bermitra dengan penyedia bahan baku pembuatan alat.

\section{ix. Struktur Biaya (Cost Stucture)}

Struktur biaya menggambarkan biaya yang wajib dikeluarkan oleh suatu perusahaan dalam mengoperasikan suatu bisnis. Biaya pengeluaran wajib CV Cipta Karya setiap bulan adalah untuk gaji karyawan, biaya operasional (listrik, pulsa paket data, $\mathrm{Wi}-\mathrm{Fi}$, dan biaya transportasi), sewa kantor dan tempat produksi, serta biaya promosi.

\section{Analisis Peta Empati Pelanggan}

Osterwalder dan Pigneur (2012) menjelaskan bahwa peta empati konsumen dibuat untuk menghasilkan model bisnis yang lebih kuat. Melalui peta empati pelanggan akan diperoleh wawasan pelanggan yang membantu dalam perancangan model bisnis walaupun tidak sepenuhnya menjadi acuan namun akan memberi gambaran terhadap CV Cipta Karya apa yang sebenarnya dibutuhkan oleh pelanggan. Berikut ini merupakan hasil yang diperoleh berdasarkan wawancara secara tidak langsung kepada 17 narasumber yang pernah membeli serta menggunakan produk CV Cipta Karya:

1. Apa yang dilihat oleh pelanggan? 
Mereka melihat bahwa penampilan produknya cukup baik.

2. Apa yang dipikirkan dan dirasakan oleh pelanggan?

Para pelanggan berpikir bahwa CV Cipta Karya merupakan produsen merek lokal. Walaupun merek lokal pelayanannya cukup memuaskan. Ketika alat tiba dengan kondisi rusak, pihak CV Cipta Karya bersedia untuk langsung memperbaikinya. Alat dengan kondisi baik memiliki suara yang cukup berkualitas. Pelayanan customer service ramah dan baik.

3. Apa yang didengar oleh pelanggan?

Menyediakan alat-alat lokal dengan harga yang lebih murah dibandingkan perusahaan lain.

4. Apa yang dikatakan dan dilakukan oleh pelanggan?

Mereka berharap produk-produk CV Cipta Karya kualitasnya dapat ditingkatkan, baik dari segi ketahanan alat maupun suaranya. Selain itu, diharapkan mampu membuat lebih banyak event yang memacu kreativitas penggiat marching band.

5. Apa yang dikorbankan oleh pelanggan?

Mengeluarkan uang cukup banyak untuk membeli alat yang lengkap. Waktu juga menjadi suatu hal untuk dikorbankan terutama yang berada di luar Yogyakarta. Mereka harus ke kantor jika ingin melihat dan mencoba alatnya secara langsung sebelum membeli.

6. Apa yang diperoleh pelanggan?

Secara keseluruhan para pelanggan cukup puas dengan kualitas dan harganya. Pelayanan juga baik, dari segi penanganan barang rusak hingga pelayanan saat negosiasi. Para pelatih juga mendapatkan komisi apabila menjadi pelanggan CV Cipta Karya.

\section{Analisis SWOT}

Analisis SWOT dapat memberikan dasar yang baik untuk diskusi lebih lanjut, pengambilan keputusan, dan akhirnya berinovasi seputar model bisnis (Osterwalder \& Pigneur, 2012). Analisis SWOT terdiri faktor internal yang terdiri dari strengths (kekuatan) dan weaknesses (kelemahan) serta faktor eksternal yang terdiri dari opportunities (peluang) dan threats (ancaman).

\section{Segmentasi Pelanggan}

Kekuatan CV Cipta Karya berperan sebagai produsen, distributor, dan kontraktor sehingga segmentasinya lebih luas. Sedangkan yang menjadi kelemahan adalah apabila telah berlangganan dengan perusahaan lain mereka tidak mudah untuk beralih. Segmen yang ditargetkan adalah kalangan menengah yang jumlahnya cukup banyak, hal ini merupakan peluang untuk CV Cipta Karya. Ancaman bagi perusahaan ini adalah banyak kompetitor yang menawarkan harga lebih murah, apabila pelanggan hanya melihat dari segi harga maka ada 
kemungkinan akan beralih ke perusahaan lain. Jika pelanggan memiliki anggaran dana lebih maka mereka akan beralih ke alat impor yang lebih bagus.

\section{Proposisi Nilai}

Bentuk alat yang futuristis khususnya alat perkusi Maxpro. Kualitas yang baik dengan harga terjangkau menjadi keunggulan yang ditawarkan kepada pelanggan. Kelemahan dalam poin ini adalah belum bisa menyaingi kualitas dari produk impor yang bagus. Memiliki peluang untuk selalu bisa memperbarui alatalat yang dibutuhkan saat ini karena para karyawan merupakan orang yang berkecimpung secara langsung di marching band. Ancaman yang mungkin terjadi adalah apabila ada kompetitor yang meniru model alat Maxpro dan bisa memberi inovasi lebih baru dibandingkan CV Cipta Karya serta bisa memberi harga lebih murah dengan kualitas yang sama bahkan lebih baik.

\section{Saluran}

Aktif di media sosial serta kerja sama dengan para pelatih cukup baik dan dekat. Kekuatan yang lain adalah di dalam segala kondisi, mampu berpartisipasi di berbagai event sehingga tetap menunjukkan bahwa perusahaan ini tetap aktif. Kelemahan dalam saluran, yaitu masih banyak daerah yang belum bisa dijangkau untuk memperkenalkan secara langsung produk CV Cipta Karya. Memiliki relasi dengan beberapa event organizer dan pembuat acara, hal ini memberi peluang untuk CV Cipta Karya terlibat dalam event yang ditangani dan diselenggarakan oleh pihak tersebut. Ketika ada pandemi atau bencana alam merupakan sebuah ancaman untuk menyalurkan produk.

\section{Hubungan Pelanggan}

Berbaur dengan komunitas pelatih marching band, memberikan komisi kepada pelatih langganan, memberi diskon apabila membeli secara paket, dan garansi terhadap kerusakan alat dari perusahaan menjadi kekuatan dari CV Cipta Karya. Masih banyak komunitas pelatih dan unit marching band yang belum dijangkau. Hal tersebut menjadi satu kelemahan dalam perusahaan ini. Memiliki peluang untuk mengadakan kegiatan sendiri dengan dukungan dari para pelatih. Menjadi ancaman apabila ada konflik antara pelanggan dan perusahaan kemungkinan akan beralih ke produk lain.

\section{Arus Pendapatan}

Kekuatan yang telah dimiliki adalah karyawan khusus keuangan sehingga pengeluaran dan pemasukan bisa terkontrol dengan baik. Direktur saat ini teliti dalam pemeriksaan laporan keuangan sehingga sulit bagi karyawan untuk memanipulasi. Kelemahannya karena harga yang ditawarkan murah maka, keuntungan yang diperoleh sedikit sehingga harus dikejar kuantitasnya. Memiliki peluang untuk melaksanakan tender dari pemerintah karena CV Cipta Karya juga berperan sebagai kontraktor yang telah memiliki legalitas sehingga bisa mendapatkan pendapatan yang cukup besar dari proyek ini. Ancamannya ketika 
kegiatan marching band tidak aktif dan proyek yang cukup besar belum melunasi hutang terhadap perusahaan dapat menyebabkan kerugian.

\section{Sumber Daya Utama}

Para karyawan yang berkompeten dan legalitas perusahaan menjadi kekuatan CV Cipta Karya. Kelemahan untuk sumber daya utama, yaitu kadangkadang belum mampu menalangi sendiri modal yang besar di awal. Apabila tidak ada orderan karyawan perajin harus dicarikan kesibukan agar tidak mengundurkan diri. Memiliki peluang untuk menciptakan lapangan pekerjaan baru di bidang marching band dan memiliki ancaman jika karyawan perajin mengundurkan diri akan sulit mencari perajin yang benar-benar paham tentang alat musik.

\section{Aktivitas Utama}

Bergerak sebagai produsen, distributor resmi, dan kontraktor. Memiliki kelemahan jika menunggu sparepart yang tidak diproduksi sendiri maka, proses produksi akan terhambat dan membutuhkan waktu lebih lama. CV Cipta Karya berpeluang untuk mencakup pasar yang lebih luas karena berperan lebih dari satu bidang. Ancaman yang akan terjadi apabila suatu saat marching band sudah tidak ada maka seluruh kegiatan tidak akan bisa berjalan.

\section{Kemitraan Utama}

Memiliki kenalan dengan pemegang merek sehingga bisa menjadi distributor resmi. Kelemahannya adalah direktur yang harus menangani mitra utama. Memiliki peluang untuk menjadi distributor yang direkomendasikan kepada pelanggan oleh pemegang merek-merek tertentu. Ancaman yang muncul adalah ketika tidak memenuhi target penjualan maka perizinan sebagai distributor resmi akan dicabut.

\section{Struktur Biaya}

Memiliki kekuatan dengan adanya sistem tutup buku dan laporan keuangan setiap bulan. Kelemahannya modal yang masih terbatas. Memiliki peluangnya untuk meminjam modal ke koperasi karena selalu melunasi tepat waktu. Ancamannya adalah beban biaya operasional yang makin meningkat.

\section{E. Implementasi Business Model Canvas}

Berdasarkan analisis peta empati pelanggan dan analisis SWOT maka diperoleh bisnis model kanvas baru untuk diimplementasikan oleh CV Cipta Karya adalah sebagai berikut:

\begin{tabular}{|l|l|l|l|l|}
\hline KP & KA & VP & CR & CS \\
• Pemegang & $\bullet$ Produsen & $\bullet$ Alat perkusi & $\begin{array}{l}\text { Pendekatan } \\
\text { personal }\end{array}$ & • Seluruh unit \\
merek alat & alat\&kostum & Maxpro & oleh & band di \\
musik & $\bullet$ Distributor & dengan & karyawan\& & Indonesia \\
& $\bullet$ Ekspedisi & resmi & desain & sales \\
pengiriman & $\bullet$ Kontraktor & futuristik & executive & \\
barang & & $\bullet$ Kualitas &
\end{tabular}


Tulisan berwarna merah merupakan perubahan yang diperoleh dari hasil analisis peta empati dan SWOT.

\section{KESIMPULAN}

Melalui kanvas model bisnis, CV Cipta Karya memiliki panduan untuk melakukan inovasi untuk produknya agar sesuai dengan kebutuhan pasar. Setelah dilakukan evaluasi dengan menggunakan analisis SWOT dan peta empati pelanggan, kanvas model bisnis yang telah diterapkan saat ini terdapat lima tambahan perubahan. Perubahan tersebut terjadi pada poin key partnership (kemitraan utama) yaitu ditambahkan pelatih marching band; value proposition (proposisi nilai) yaitu mengutamakan pelayanan yang baik untuk pelanggan; customer relationship (hubungan pelanggan) yaitu terdapat perubahan agar pendekatan kepada konsumen tidak hanya dilakukan oleh direktur namun oleh 
karyawan terutama tim pemasaran dan sales executive; dan channel (saluran) yaitu dengan membuka toko di beberapa daerah dan sales executive wajib memiliki contoh barang. Setelah ditemukan kanvas model bisnis yang baru diharapkan akan diimplementasikan oleh CV Cipta Karya dan diadakan evaluasi secara berkala.

\section{KEPUSTAKAAN}

Amirullah. (2013). Metodologi Penelitian Manajemen: Disertai Contoh Judul Penelitian dan Proposal. Malang: Banyumedia Publishing, Anggota IKAPI.

Kurniasari, Riza \& Kartikasari, Dwi. (Maret 2018). "Penerapan Model Bisnis Kanvas Terhadap Jasa Angkut Penumpang pada PT Internasional Golden Shipping". Journal of Applied Managerial Accounting, Vol.2/1, 6-14.

Kurniawan, Fajar Azmi. (Desember 2017). "Pendekatan Business Model Canvas sebagai Perancangan Strategi Bisnis Baru”. Jurnal Sketsa Bisnis, Vol.4/2, 123-135.

Moelong, Lexy J. (2013). Metodologi Penelitian Kualitatif. Bandung: PT Remaja Rosdakarya.

Novitha Herawati, Triana Lindriati \& Ida Bagus Suryaningrat. (2019). "Penerpan Bisnis Model Kanvas dalam Penentuan Rencana Manajemen Usaha Kedelai Edamame Goreng”. Jurnal Agroteknologi, Vol.13/01, 42-51.

Osterwalder, Alexander \& Pigneur Yves. (2012). Business Model Generation. Jakarta: PT Elex Media Komputindo Kelompok Gramedia, Anggota IKAPI.

Purnawati, Ni wayan \& Setyohadi, Djoko Budiyanto. (November 2017). "The Analysis of Implementation Business model Canvas At The E-Marketplace Dipeta Company". Scientific Journal of Informatics, Vol.4/2, 125-133.

Rusli M. Rukka, Nurbaya Busthanul \& Nur Fatonny. (Februari 2018). "Strategi Pengembangan Bisnis Keripik Bayam (Amaranthus hybrids) Dengan Pendekatan Business Model Canvas: Studi Kasus pada CV.OAG di Kota Makassar, Sulawesi Selatan”. Jurnal Sosial Ekonomi Pertanian, Vol.14/1, 41-54.

Salim, M. Afif \& Siswanto, Agus Bambang. (2019). Analisis SWOT Dengan Metode Kuesioner. Jakarta: Pilar Nusantara.

\section{Narasumber :}

Dhiya'ul Fajri (32 tahun), Pendiri dan Direktur CV Cipta Karya, wawancara 28 Januari 2021 di Kantor CV Cipta Karya, Yogyakarta. 